Journals supporting CONSORT should state unambiguously what they expect from authors.

In 2003, many journals gave out of date citations for both CONSORT and the ICMJE guidelines. This carelessness sets a poor example for authors. Journals should be more vigilant regarding the information in their instructions to authors, should be explicit in their expectations of adherence to specific recommendations, and should cite the web address to ensure that the latest versions are obtained along with any extensions.

I thank for helpful comments on an earlier draft from members of the CONSORT Group: Patrick Bossuyt, Frank Davidoff, Diana Elbourne, Stephen Evans, Peter Gøtzsche, David Grimes, Barbara Hawkins, John Ioannidis, Tom Lang, David Moher, Cynthia Mulrow, Roberta Scherer, and Kenneth Schulz.

Contributors: DGA is the sole contributor.
Funding: DGA is employed by Cancer Research UK, but this study had no explicit funding.

Competing interests: DGA is a member of the CONSORT Group.

Ethical approval: Not needed.

1 Moher D, Schulz KF, Altman DG for the CONSORT Group. The CONSORT statement: revised recommendations for improving the quality of reports of parallel-group randomised trials. Lancet 2001;357:1191-4.

2 Altman DG, Schulz KF, Moher D for the CONSORT Group. The revised CONSORT statement for reporting randomized trials: explanation and elaboration. Ann Intern Med 2001:134:663-94.

2 Moher D Jones A Lepage L for the CONSORT Group. Use of the CONSORT statement and quality of reports of randomised trials: a comparaive before-and-after evaluation. JAMA 2001;285:1992-5.

4 Egger M, Jüni P, Bartlett C for the CONSORT Group. Value of flow diagrams in reports of randomised controlled trials. JAMA 2001;285:1996-9. 5 Devereaux PJ, Manns BJ, Ghali WA, Quan H, Guyatt GH. The reporting of methodological factors in randomized controlled trials and the association with a journal policy to promote adherence to the consolidated standards of reporting trials (CONSORT) checklist. Control Clin Trials 2002;23:380-8.

(Accepted 2 March 2005)

\title{
Adequacy and reporting of allocation concealment: review of recent trials published in four general medical journals
}

Catherine Hewitt, Seokyung Hahn, David J Torgerson, Judith Watson, J Martin Bland

In randomised controlled trials, allocation concealment (separating the process of randomisation from the recruitment of participants) is important for rigorously designed trials. ${ }^{1-4}$ In 1996 many major medical journals adopted the CONSORT statement (whereby researchers have to include a short checklist of essential items and a flow diagram when reporting trials), ${ }^{5}$ and this move encouraged the reporting of allocation concealment. We reviewed the prevalence of adequate allocation concealment and its association with the statistical significance of trial results.

\section{Methods and results}

We searched by hand four general medical journals (the BMJ, JAMA, the Lancet, and the New England Journal of Medicine) to identify randomised controlled trials published from January 2002 to December 2002. We included articles if the authors reported that participants were randomised and if the trial was published as a full report with the results of the main analyses. We categorised articles according to whether allocation concealment was adequate (the person who executed the allocation sequence was different from the person who recruited participants), inadequate (the person who recruited participants also executed the allocation sequence), or unclear (the article failed to describe how the researchers concealed the allocation). We considered the widely used "sealed envelope" method to be inadequate unless performed by an independent third party. We used a kernel density plot to compare the $\mathrm{P}$ values of trials that used adequate concealment methods with those that used inadequate methods; we used $\mathrm{P}$ values because these were readily available across most of the trials, which used different statistical methods and outcome measures. Our statistical analyses adjusted for clustering effects by journal.

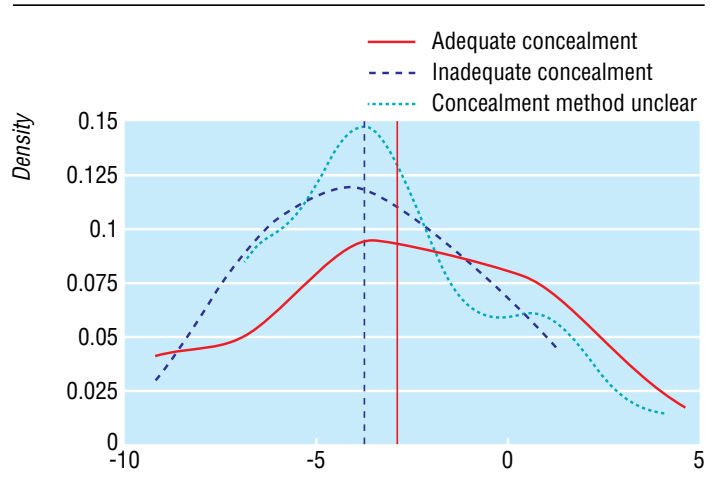

Logit ( $P$ value $)$

Distribution of $\mathrm{P}$ values by adequacy of allocation concealment. As the $P$ values were highly positively skewed, the data were transformed using the logit function. The vertical lines represent mean $P$ values for trials using adequate or inadequate concealment

Among the 234 trials that met the inclusion criteria, allocation concealment was adequate in 132 $(56 \%)$ and inadequate in $41(18 \%)$; in $61(26 \%)$ the concealment method was unclear. Of the trials whose allocation concealment was considered adequate, 118 used independent allocation (which included using a telephone, fax machine, or pager to a randomisation service); five used sealed envelopes opened by a third party; eight used a computer; and one used a combination of adequate methods. Of the 41 trials whose allocation concealment was inadequate, 39 used sealed envelopes, one selected a card from a pile, and one added the name of the next participant to the randomisation list.

This article was posted on bmj.com on 10 March 2005: http://bmj.com/ cgi/doi/10.1136/bmj.38413.576713.AE
York Trials Unit, Department of Health Sciences, University of York, York YO10 5DD

Catherine Hewitt PhD student David J Torgerson Judith Watson research fellow J Martin Bland professor of health statistics

Medical Research

Collaborating Center, Seoul National University Hospital/College o Medicine, Seoul 110-744, Korea Seokyung Hahn assistant professor

Correspondence to: C Hewitt ceh121@york.ac.uk

BMJ 2005;330:1057-8 


\section{What is already known on this topic}

The effect of adequacy of allocation concealment in randomised controlled trials may influence the degree of effect

\section{What this study adds}

Despite researchers' acceptance that adequate allocation concealment is important, almost a fifth of trials recently published in major medical journals used inadequate concealment and a quarter failed to describe how the allocation was concealed

For $28(17 \%)$ of the 166 trials published in the CONSORT journals (the BMJ, the Lancet, and JAMA) and $33(49 \%)$ of the 68 trials published in the non-CONSORT journal (the New England Journal of Medicine) we could not discern whether allocation was adequately concealed. We excluded 97 of the original 234 trials from the $\mathrm{P}$ value analysis because a single $\mathrm{P}$ value was not extractable (for example, unclear primary outcome). The figure shows a trend towards lower $\mathrm{P}$ values for inadequately concealed trials (mean $=0.022) ; \mathrm{P}$ values from trials that used adequate methods were more widely spread around a higher mean value (0.052). The difference between these two mean values was significant $(\mathrm{P}=0.045)$. In a logistic regression, adjusted for sample size and journal, we found that the odds of a trial with inadequate concealment yielding a significant result $(\mathrm{P} \leq 0.05)$ compared with a trial with adequate concealment was 1.8 (95\% confidence interval 0.8 to 3.7$)$, thus suggesting that trials using inadequate concealment tend to show significant differences between the groups in the primary outcome more often than trials using adequate concealment.

\section{Comments}

We found that despite the CONSORT statement more than $40 \%$ of trials published in major medical journals either did not use adequate methods or failed to describe how they concealed the allocation. Our results confirm the association found in previous studies that trials using inadequate allocation concealment are more likely to report significant findings than those using adequate concealment. Readers should critically assess the reported methods of allocation concealment.

We thank Doug Altman for reviewing an earlier version of the paper and providing valuable feedback. A list of included studies is available on request from $\mathrm{CH}$.

Contributors: DJT suggested the idea of the review. CH, DJT, and JW did the searches and extracted data from the included papers. $\mathrm{CH}$, with advice from $\mathrm{SH}$ and JMB, undertook the data analysis. $\mathrm{CH}$ wrote the paper, and JMB, SH, DJT, and JW commented on it. $\mathrm{CH}$ is the guarantor.

Funding: Department of Health Sciences, University of York.

Competing interest statement: None declared.

Ethical approval: Not needed.

1 Juni P, Altman DG, Egger M. Systematic reviews in health care: assessing the quality of controlled clinical trials. BMJ 2001;323:42-6.

Schulz KF, Chalmers I, Hayes RJ, Altman DG. Empirical evidence of bias: dimensions of methodological quality associated with estimates of treatment effects in controlled trials. JAMA 1995;273:408-12.

3 Chalmers T, Celano P, Sacks H, Smith H. Bias in treatment assignment in controlled clinical trials. N Engl J Med 1983;309:1358-61.

4 Emerson JD, Burdick E, Hoaglin DC, Mosteller F, Chalmers TC. An empirical study of the possible relation of treatment differences to quality scores in controlled randomized clinical trials. Control Clin Trials ity scores in contron

5 Altman DG, Schulz KF, Moher D, Egger M, Davidoff F, Elbourne D, et al. The revised CONSORT statement for reporting randomized trials: explanation and elaboration. Ann Intern Med 2001;134:663-94.

(Accepted 28 January 2005)

doi 10.1136/bmj.38413.576713.AE

\section{Foreign "doctors"}

Earlier this year our batch of medical students had been to different hospitals in the periphery of the kingdom of Nepal for the college curriculum "District health and hospital management." Immediately after the New Year we were in the Mission Hospital in the western part of the country, where we observed different departments and wards to understand the management of the hospital.

One day I was observing a male outpatient clinic, where an experienced Nepali doctor was examining the patients. After a name was called two people entered the room, one the patient and the other his educated relative. When it was clear that the patient could explain himself perfectly well, the doctor asked the relative to wait outside in the corridor.

A minute later, however, he reappeared with a fair skinned, Western foreigner who had just been walking down the corridor. To my surprise, he then asked this rather bemused foreigner to examine the patient, who was giving his history to the Nepali doctor. The doctor and the foreigner had a talk, and the foreigner explained to the relative in broken Nepali that he had explained everything to the doctor. The relative seemed satisfied with this and went outside again to let the doctor continue the consultation.

Later we found that the foreigner was not even medically qualified but was helping with the electronic instruments in the hospital.
Nepalese have great respect for foreigners (especially fair skinned ones), and the patients at the mission hospital tended to be dissatisfied if they were not examined by one of the foreign doctors working there, whatever qualification and experience they might have. The local people consider foreigners to be experts, and even the people from the border area of India come to the hospital to be examined by the foreign doctors despite having access to better hospitals. The thinking that foreigners can treat any disease is widely prevalent in the country, and affluent families in the cities prefer to go to Europe and the United States for medical treatment even though sophisticated and specialised local centres have been established.

Laxmi Vilas Ghimire student, Institute of Medicine, Sundhara, Kathmandu,Nepal (vilas_laxmi@iom.edu.np)

We welcome articles up to 600 words on topics such as A memorable patient, A paper that changed my practice, My most unfortunate mistake, or any other piece conveying instruction, pathos, or humour. Please submit the article on http:// submit.bmj.com Permission is needed from the patient or a relative if an identifiable patient is referred to. We also welcome contributions for "Endpieces," consisting of quotations of up to 80 words (but most are considerably shorter) from any source, ancient or modern, which have appealed to the reader. 